\title{
ANALISA JUMLAH MESIN IDEAL UNTUK MENCAPAI KESEIMBANGAN LINI PRODUKSI DI PT. XYZ
}

\author{
Afif Hakim \\ Program Studi Teknik Industri, Universitas Buana Perjuangan Karawang \\ Jl. HS. Ronggowaluyo Telukjambe Timur, Karawang 41361 \\ email: afif.hakim@ubpkarawang.ac.id
}

\begin{abstract}
ABSTRAK
Pengukuran jumlah mesin ideal sangat diperlukan untuk melihat kapasitas produksi mencukupi ataukan tidak yang pada akhirnya akan menentukan kelancaran pengiriman barang jadi kepada customer. Metode yang digunakan dalam penelitian ini adalah dengan menghitung kecukupan jumlah mesin di tiap lini yang ada dengan mempertimbangkan waktu siklus, proporsi cacat, jumlah permintaan dan efisiensi mesin yang ditetapkan oleh perusahaan. Dengan penambahan ini, diharapkan tidak akan ada kerja lembur untuk mengejar target produksi.

Hasil pengecekan terhadap jumlah mesin menunjukkan bahwa agar tercapainya keseimbangan lintasan produksi sehingga nantinya dapat meningkatkan kapasitas produksi, terdapat beberapa mesin tertentu yang memerlukan penambahan unit yaitu total sebanyak 15 unit untuk 14 Operation (masing-masing Operation membutuhkan 1 unit tambahan tetapi ada 1 Operation yang membutuhkan 2 tambahan unit mesin). Disamping itu ada juga mesin tertentu yang perlu dilakukan pengurangan unit untuk tujuan efisiensi yaitu sebanyak 3 unit mesin dari 2 Operation. Hal ini dikarenakan kapasitasnya sudah memenuhi permintaan tanpa mesin-mesin tersebut, dan sebagian besar jumlah mesin dinilai sudah ideal antara kebutuhan secara teoritis dengan keadaan saat ini.
\end{abstract}

Kata Kunci: Jumlah mesin ideal, kapasitas produksi, waktu siklus, proporsi cacat, efisiensi

\section{PENDAHULUAN}

Di abad modern ini, perkembangan ilmu pengetahuan dan teknologi mengalami kemajuan yang sangat pesat dan mengagumkan sehingga persaingan antar perusahaan semakin ketat. Hal ini mengharuskan perusahaan untuk selalu melakukan pembenahan dalam setiap lini corporate system-nya. Perusahaan yang tidak menerapkan prinsip continous improvement dapat dipastikan usianya tidak akan bertahan lama. 
Begitu pula halnya dengan PT. XYZ. Sebagai sebuah perusahaan manufaktur yang semakin dewasa dan terus berkembang, perusahaan ini selalu siap bersaing dengan kompetitor dalam produk yang sama. Untuk mempertahankan pasar yang telah berhasil diraih, PT. XYZ melakukan berbagai upaya menuju ke arah kualitas produk yang semakin sempurna, standarisasi internasional dan kepercayaan konsumen serta prinsip kemandirian. PT.XYZ sebagai perusahaan yang berbasis make to order harus dapat mempertahankan para konsumennya agar tidak mudah berpindah kepada produsen lain. Bentuk nyata dari semua itu adalah Perusahaan harus bisa memenuhi permintaan pelanggan dalam jumlah dan waktu yang tepat sesuai kesepakatan. Oleh karena itu, sangat diperlukan sekali perencanaan produksi yang baik dan dapat diandalkan sehingga tidak merugikan kedua belah pihak. Perencanaan produksi bertujuan untuk menentukan aktifitas produksi secara lebih rinci pada lini produksi yang biasanya dituangkan dalam jadwal induk produksi yang berisi produk apa saja yang akan dibuat dan kapan membuatnya (Heizer \& Render, 2004)

Perencanaan produksi sebagai dasar dalam melakukan produksi haruslah dapat menyatukan antara permintaan konsumen dengan kapasitas produksi yang dimiliki. PT. XYZ berusaha untuk selalu menyanggupi permintaan dari konsumen walaupun sesekali pada kenyataannya permintaan tersebut melebihi kapasitas yang dimilikinya. Hal ini menyebabkan jumlah aktual produksi terkadang dibawah jumlah yang telah direncanakan sehingga menyebabkan perusahaan seringkali mengadakan kerja lembur yang memerlukan biaya tidak sedikit. Berdasarkan latar belakang di atas maka diperlukan analisa apakah jumlah mesin produksi terutama di bagian Machining sudah mencukupi ataukah masih diperlukan penambahan mesin.

\section{TINJAUAN PUSTAKA}

Penentuan kebutuhan kapasitas produksi merupakan persoalan utama yang tidak hanya timbul pada saat perancangan awal suatu sistem baru. Akan tetapi, persoalan kapasitas produksi juga seringkali muncul ketika suatu perusahaan tidak mampu atau selalu kurang dalam memenuhi permintaan konsumen. Kapasitas produksi diukur dalam satuan unit fisik yang menyatakan tingkat output maksimum untuk produk ataupun jumlah dari sumberdaya-sumberdaya utama yang tersedia dalam setiap periode operasi (Nasution, 2006). Untuk dapat menentukan kapasitas produksi yang optimum, terdapat berbagai faktor yang harus diperhatikan seperti ketersediaan bahan baku, ketersediaan jam kerja mesin, ketersediaan jam kerja operator, modal kerja yang dimiliki, dan jumlah permintaan. Faktor-faktor tersebut dikombinasikan untuk mencapai hasil yang optimum (keuntungan maksimum dan biaya minimum). 
Dalam pembuatan sebuah produk maka proses produksi dapat diselenggarakan melalui satu tahapan proses (one-stage) atau melalui beberapa tahapan (multiplestage). Bilamana proses produksi terdiri hanya satu tahapan saja maka penetapan kapasitas produksi dari mesin atau fasilitas lainnya ditentukan secara langsung berdasarkan output rate dari sistem produksi tersebut (Wignjosoebroto, 1996). Pada kenyataanya, sebagian besar produksi memerlukan serangkaian tahapan proses untuk membuat sebuah produk. Setiap tahapan proses tersebut tentunya memiliki kapasitas yang berbeda-beda sehingga seringkali terjadi ketidaklancaran aliran produksi atau yang sering disebut dengan bottleneck. Bottleneck dapat didefinisikan sebagai penumpukan material di suatu stasiun kerja atau tahapan proses karena disebabkan perbedaan kapasitas stasiun kerja tersebut. Perbedaan kapasitas tersebut utamanya disebabkan oleh perbedaan waktu siklus tiap stasiun kerja, waktu yang tersedia, dan tingkat kecacatan.

Kapasitas produksi yang memerlukan beberapa tahapan proses akan lebih sulit perhitungannya dari pada yang hanya memerlukan satu tahap proses saja. Pada produksi yang hanya terdapat satu tahap proses, tingkat output (output rate) yang dihasilkan akan dapat dikaitkan langsung dengan kapasitas proses atau mesin yang digunakan. Sedangkan pada produksi yang terdiri dari serangkaian tahapan proses yang kompleks, akan sangat sulit dan tidak mungkin untuk memasang setiap tahapan proses dengan kapasitas maksimum yang sama. Akibatnya adalah kemungkinan terjadinya penyumbatan-penyumbatan arus aliran material pada stasiun kerja tertentu yang mempunyai kapasitas yang kecil. Oleh karena itu, biasanya diperlukan studi lebih lanjut untuk menyeimbangkan lintasan produksi (line balancing) sehingga dapat dicapai keadaan paling optimum atau paling seimbang, tidak harus sama, antara kapasitas suatu stasiun kerja dengan stasiun kerja yang lain dalam lini produksi.

Beberapa metode telah dibuat oleh para ahli untuk mengatasi kecemasankecemasan akibat ketidakseimbangan kapasitas tersebut dari mulai metode yang rumit hingga metode yang sangat sederhana. Beberapa cara sederhana yang membutuhkan sedikit perhitungan adalah dengan pengadaan working process storage dan penempatan fasilitas produksi seperti penambahan mesin secara paralel khususnya untuk tahapan proses yang menimbulkan bottle necks. Penentuan jumlah mesin yang ideal perlu dilakukan agar dapat meminimalisir terjadinya bottle necks sehingga kapasitas produksi secara keseluruhan tahapan proses dapat meningkat. Untuk keperluan penentuan jumlah mesin yang dibutuhkan maka disini ada beberapa informasi yang harus diketahui sebelumnya, yaitu:

- Volume produksi yang dicapai atau permintaan

- Estimasi skrap pada setiap proses operasi 
- Waktu kerja standard untuk proses operasi yang berlangsung.

Selanjutnya untuk menentukan jumlah mesin dalam hal ini bisa pula untuk menentukan jumlah operator yang diperlukan berdasarkan informasi-informasi tersebut, maka rumus umum yang dapat digunakan adalah sebagai berikut (Wignjosoebroto, 1996).

Dimana:

$$
N=\frac{T}{60} \frac{P}{D E}
$$

P jumlah produk yang akan dibuat oleh mesin per periode waktu kerja

$\mathrm{T}$ total waktu pengerjaan yang dibutuhkan untuk proses operasi produksi yang diperoleh dari hasil time study atau perhitungan secara teoritis (menit)

D jam operasi kerja mesin yang tersedia (jam)

E faktor efisiensi kerja mesin yang disebabkan oleh adanya set up, break down, repair atau hal-hal lain yang menyebabkan terjadinya idle. Harga yang umum diambil dalam hal ini berkisar antara 0,8 0,9

$\mathrm{N}$ jumlah mesin atau operator yang dibutuhkan untuk operasi produksi

Kenyataan yang sering dijumpai ialah bahwa produksi dengan output $100 \%$ berkualitas baik semua akan sangat sulit tercapai. Oleh karena itu, perlu dipertimbangkan faktor kelonggaran (allowance) dengan memperhatikan adanya beberapa unit produk yang cacat dari hasil produksi tersebut. Dengan demikia, jumlah produk yang akan dibuat (input) dapat dirumuskan sebagai berikut (Wignjosoebroto, 1996).

Dimana:

$$
P=P_{g}+P_{d}
$$

$\mathrm{P} \quad$ jumlah produk yang akan diproses oleh suatu mesin (input)

$\mathrm{P}_{\mathrm{g}} \quad$ jumlah produk yang good (good parts)

$\mathrm{P}_{\mathrm{d}} \quad$ jumlah produk yang not good (defective parts)

Jumlah produk yang cacat ini dapat pula dinyatakan dalam bentuk prosentase kerusakan ( $p$ ) dari jumlah produk yang berkualitas baik, sehingga rumus diatas dapat disesuaikan menjadi sebagai berikut.

$$
P=\frac{P_{g}}{(1-p)}
$$

Prosentase produk yang rusak ini dapat diperkirakan salah satunya dengan cara mengambil sample hasil keluaran dari suatu proses produksi pada waktu tertentu. 
Selain itu khususnya untuk kondisi pabrik yang baru estimasi ini dapat pula dicari dengan cara membandingkan kondisi dan pengalaman dari pabrik yang lain, dengan tahapan proses yang sama atau hampir sama. Perlu dicatat disini bahwa $\mathrm{P}$ adalah jumlah produk yang merupakan input untuk suatu proses produksi untuk membuat sejumlah output produk yang diinginkan sesuai permintaan. Apabila suatu proses di dalam pembuatannya memerlukan bermacam-macam tahapan proses, maka terjadinya kerusakan harus pula dianalisa untuk setiap tahapan proses yang ada.

Dengan demikian dapat disimpulkan bahwa semakin banyak tahapan proses yang harus dibutuhkan untuk membuat suatu produk, maka akan semakin besar pula resiko-resiko yang akan terjadi seperti timbulnya produk cacat yang semakin banyak, lose time yang besar, dan sebagainya. Banyaknya produk yang cacat dari masing-masing tahapan proses tergantung pada karakteristik operasi yang ada di masing-masing tahapan proses tersebut seperti kondisi mesin atau peralatan itu sendiri, efektivitas perawatan yang dilakukan, kemampuan operator yang dipekerjakan dan lain-lain. Pembuatan produk yang terdiri dari beberapa tahapan proses dapat dijelaskan dengan hubungan dari jumlah produk yang harus dibuat serta kemungkinan terjadinya produk yang cacat untuk masing-masing tahapan proses. Berikut adalah rumus yang dapat digunakan untuk mencari jumlah input pada masing-masing tahapan proses.

$$
P_{g, i-1}=\frac{P_{g, i}}{\left(1-p_{i-1}\right)}
$$

Dimana:

$\mathrm{P}_{\mathrm{g}, \mathrm{i}-1}$ jumlah produk good yang merupakan output dari tahapan proses ke i-2 dan input untuk tahapan proses yang ke i-1

$\mathrm{P}_{\mathrm{g}, \mathrm{i}} \quad$ jumlah produk good yang merupakan output dari tahapan proses ke i-1 dan input untuk tahapan proses ke i

$\mathrm{p}_{\mathrm{i}} \quad$ estimasi prosentase cacat proses ke i-1

Produk yang cacat dapat dibedakan menjadi dua macam, yaitu cacat yang memang tidak dapat diperbaiki kembali dan cacat yang masih dapat diperbaiki (repair). Dengan demikian, maka penentuan jumlah mesin atau peralatan produksi jika produk not good (rusak) ternyata tidak dapat diperbaiki lagi dapat dinyatakan sebagai rumus berikut (Wignjosoebroto, 1996).

$$
N_{i}=\frac{T_{i}}{60} \frac{P_{i}}{D E_{i}} \quad ; i=1,2, \ldots, n
$$

Dimana:

P jumlah produk yang harus dibuat oleh mesin ke i per periode waktu kerja 
$\mathrm{T}$ total waktu pengerjaan yang dibutuhkan untuk proses operasi produksi pada mesin ke i (menit)

D jam operasi kerja mesin yang tersedia (jam)

E faktor efisiensi kerja mesin ke i

$\mathrm{N} \quad$ jumlah mesin ke i yang dibutuhkan untuk operasi produksi

Jika berdasarkan pertimbangan teknis maupun ekonomis ternyata masih dimungkinkan untuk melakukan perbaikan pada produk yang cacat tersebut, maka perlu diperhitungkan kebutuhan tambahan untuk mesin maupun peralatan produksi yang lainnya dan juga operator yang akan melakukan aktivitas ini. Aktivitas ini dapat dilaksanakan dalam area yang sama dari departemen produksi yang ada ataupun dalam area khusus mengingat bahwa mungkin akan diperlukan peralatan yang berbeda. Kebutuhan peralatan tambahan ini dapat dicari dengan model perumusan yang sama, yaitu sebagai berikut (Wignjosoebroto, 1996).

$$
N_{i}^{\prime}=\frac{T_{i}^{\prime}}{60} \frac{P_{i}^{\prime}}{D E_{i}^{\prime}}
$$

Dimana:

i tahapan proses dimana aktivitas perbaikan dari produk yang cacat atau rusak akan dilaksanakan

$\mathrm{T}_{\mathrm{i}}^{\prime} \quad$ waktu yang dibutuhkan untuk melaksanakan perbaikan dari unit produk yang rusak pada tahapan proses ke i (menit)

$\mathrm{P}_{\mathrm{i}}^{\prime} \quad$ Jumlah produk yang rusak yang memiliki kemungkinan untuk bisa diperbaiki lagi pada tahapan proses ke $\mathrm{i}$

$\mathrm{N}_{\mathrm{i}}^{\prime} \quad$ Jumlah mesin/peralatan tambahan yang dibutuhkan untuk pelaksanaan perbaikan pada tahap proses ke $\mathrm{i}$

D waktu yang tersedia untuk proses perbaikan produk

Apabila aktivitas perbaikan ini dilaksanakan pada tahapan proses yang sama dan dengan memakai mesin atau peralatan produksi yang sama pula, maka total mesin ataupun peralatan produksi yang dibutuhkan untuk tahapan proses ke i adalah sebesar $\mathrm{N}_{\mathrm{i}}+\mathrm{N}^{\prime}$. Faktor efisiensi dapat berupa ketentuan atau kebijakan dari pihak manajemen perusahaan ataupun dapat dicari dengan menggunakan rumus sebagai berikut (Wignjosoebroto, 1996).

$$
E=\frac{H}{D}=1-\frac{D_{T}+S_{T}}{D}
$$

Dimana:

$\mathrm{H} \quad$ Running time yang diharapkan perperiode (jam)

D Lama waktu kerja per periode (jam)

$\mathrm{D}_{\mathrm{T}} \quad$ Down time (jam)

$\mathrm{S}_{\mathrm{T}} \quad$ Set-up time untuk proses pengerjaan per periode (jam) 


\section{METODOLOGI PENELITIAN}

Tahapan-tahapan penelitian secara umum dapat pula dilihat dalam diagram alir penelitian berikut ini :

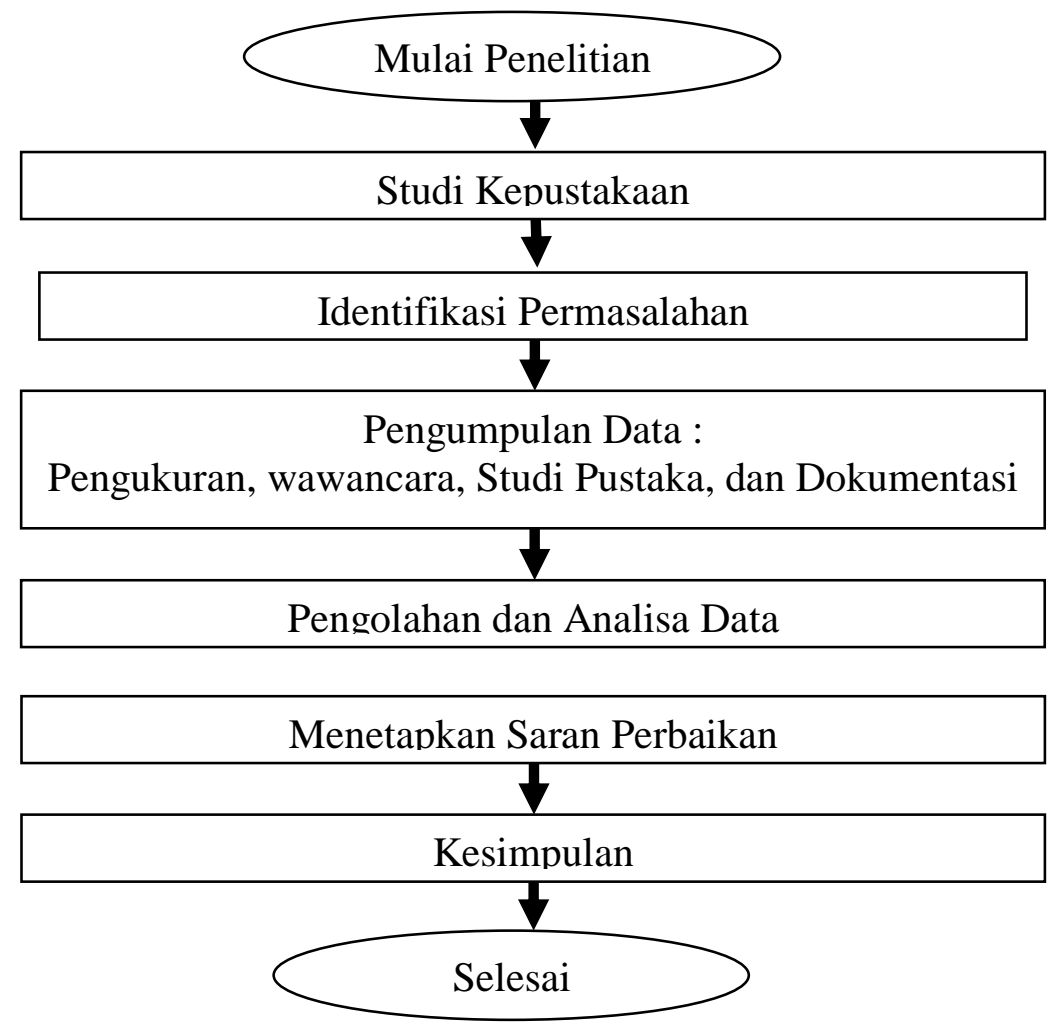

Gambar 1. Alur Penelitian

\section{HASIL DAN PEMBAHASAN}

Perhitungan penentuan kuantitas produksi pada departemen machining bergantung pada permintaan (PO) departemen sesudahnya (masing-masing part berbeda-beda), stock awal, dan rencana stock yang diinginkan. Rumusnya adalah sebagai berikut :

$$
\text { Produksi }=\text { jumlah } P O+\text { rencana stoock }- \text { stock awal }
$$

Setelah didapatkan produksi perbulan, maka selanjutnya menghitung produksi pershift dengan membaginya dengan 64 shift (dalam satu bulan terdiri dari 64 shift). Berikut ini adalah hasil perhitungan jumlah produksi per shift yang didapatkan. 
Tabel 1. Jumlah produksi per shift

\begin{tabular}{|c|l|c|c|c|c|c|}
\hline No & \multicolumn{1}{|c|}{ Nama Produk } & $\begin{array}{c}\text { Jumlah } \\
\text { PO } \\
\text { unit/bln) }\end{array}$ & $\begin{array}{c}\text { Stock } \\
\text { Awal } \\
\text { (unit/bln) }\end{array}$ & $\begin{array}{c}\text { Rencana } \\
\text { Stock } \\
\text { (unit/bln) }\end{array}$ & $\begin{array}{c}\text { Produksi } \\
\text { unit/bln) }\end{array}$ & $\begin{array}{c}\text { Produksi } \\
\text { Per shift } \\
\text { (unit) }\end{array}$ \\
\hline 1 & Hub Rear 2F5 & 9900 & 0 & 1100 & 11000 & 172 \\
\hline 2 & Hub Rear KPW & 37500 & 0 & 0 & 37500 & 586 \\
\hline 3 & Hub Fr Disk KWF & 30000 & 0 & 0 & 30000 & 469 \\
\hline 4 & JT. Carburetor 4D0 & 56040 & 0 & 6460 & 62500 & 977 \\
\hline 5 & Master Cylinder KWFF & 106400 & 0 & 3100 & 109500 & 1711 \\
\hline 6 & Master Cylinder KGFT & 37500 & 0 & 2500 & 40000 & 625 \\
\hline 7 & Master Cylinder KVBS & 5500 & 0 & 1700 & 7200 & 113 \\
\hline 8 & Master Cylinder NDF & 102600 & 0 & 6600 & 109200 & 1707 \\
\hline 9 & Caliper KWFF & 97856 & 0 & 3544 & 101400 & 1585 \\
\hline 10 & Caliper KGFT & 30303 & 0 & 7197 & 37500 & 586 \\
\hline 11 & Caliper KKFG & 24400 & 0 & 5600 & 30000 & 469 \\
\hline 12 & Panel KTMK & 70925 & 2452 & 2800 & 71273 & 1114 \\
\hline 13 & Panel KCPV & 18750 & 0 & 1250 & 20000 & 313 \\
\hline 14 & FFD NDF & 7700 & 1000 & 0 & 6700 & 105 \\
\hline 15 & FFD KWFF & 23607 & 0 & 6000 & 29607 & 463 \\
\hline
\end{tabular}

Setelah didapatkan jumlah produksi pershift untuk masing-masing part, maka selanjutnya adalah menghitung jumlah input yang harus diproses pada masingmasing mesin dengan rumus :

$$
P=\frac{P_{g}}{(1-p)}
$$

Berikut ini adalah tabel lengkap hasil perhitungan jumlah input pada masingmasing mesin yang didapatkan :

Tabel 2. Jumlah input untuk masing-masing Operation

\begin{tabular}{|c|l|c|c|c|}
\hline No & Nama Produk & $\begin{array}{c}\text { Nama } \\
\text { Proses }\end{array}$ & $\begin{array}{c}\text { Estimasi } \\
\text { Cacat rata-rata (\%) }\end{array}$ & $\begin{array}{c}\text { Jumlah Input } \\
\text { (unit) }\end{array}$ \\
\hline 1 & Hub Rear 2F5 & OP1 & 2 & 188 \\
\hline & & OP2 & 3 & 184 \\
\hline & & OP3 & 2 & 178 \\
\hline & & OP4 & 1 & 174 \\
\hline 2 & Hub Rear KPW & OP1 & 2 & 638 \\
\hline & & OP2 & 1 & 625 \\
\hline & & OP3 & 2 & 618 \\
\hline & & OP4 & 2 & 605 \\
\hline & & OP5 & 1 & 592 \\
\hline 3 & Hub Fr Disk KWF & OP1 & 2 & 516 \\
\hline & & OP2 & 3 & 505 \\
\hline
\end{tabular}




\begin{tabular}{|c|c|c|c|c|}
\hline & & OP3 & 2 & 489 \\
\hline & & OP4 & 1 & 479 \\
\hline & & OP5 & 1 & 474 \\
\hline \multirow[t]{2}{*}{4} & JT. Carburetor 4D0 & OP1 & 2 & 1018 \\
\hline & & OP2 & 2 & 997 \\
\hline \multirow[t]{5}{*}{5} & Master Cylinder KWFF & OP1 & 1 & 1729 \\
\hline & & OP2 & 2 & 1856 \\
\hline & & OP3 & 2 & 1800 \\
\hline & & OP4 & 1 & 1764 \\
\hline & & OP5 & 2 & 1746 \\
\hline \multirow[t]{2}{*}{6} & Master Cylinder KGFT & OP1 & 2 & 652 \\
\hline & & OP2 & 2 & 638 \\
\hline \multirow[t]{3}{*}{7} & Master Cylinder KVBS & OP1 & 2 & 123 \\
\hline & & OP2 & 3 & 120 \\
\hline & & OP3 & 2 & 116 \\
\hline \multirow[t]{4}{*}{8} & Master Cylinder NDF & OP1 & 2 & 1833 \\
\hline & & OP2 & 1 & 1796 \\
\hline & & OP3 & 2 & 1778 \\
\hline & & OP4 & 2 & 1742 \\
\hline \multirow[t]{3}{*}{9} & Caliper KWFF & OP1 & 2 & 1653 \\
\hline & & OP2 & 1 & 1619 \\
\hline & & OP3 & 1 & 1602 \\
\hline \multirow[t]{2}{*}{10} & Caliper KGFT & OP1 & 2 & 611 \\
\hline & & $\mathrm{OP} 2$ & 2 & 598 \\
\hline \multirow[t]{2}{*}{11} & Caliper KKFG & OP1 & 2 & 489 \\
\hline & & OP2 & 2 & 479 \\
\hline \multirow[t]{3}{*}{12} & Panel KTMK & OP1 & 1 & 1173 \\
\hline & & $\mathrm{OP} 2$ & 2 & 1161 \\
\hline & & OP3 & 2 & 1137 \\
\hline \multirow[t]{3}{*}{13} & Panel KCPV & OP1 & 2 & 334 \\
\hline & & $\mathrm{OP} 2$ & 1 & 327 \\
\hline & & OP3 & 3 & 232 \\
\hline \multirow[t]{2}{*}{14} & FFD NDF & OP1 & 3 & 112 \\
\hline & & OP2 & 2 & 108 \\
\hline \multirow[t]{3}{*}{15} & FFD KWFF & OP1 & 2 & 498 \\
\hline & & OP2 & 2 & 488 \\
\hline & & OP3 & 3 & 478 \\
\hline
\end{tabular}

Setelah perhitungan input untuk tiap mesin didapatkan, selanjutnya adalah menghitung jumlah mesin yang ideal. Oleh karena waktu siklus dalam skala detik maka rumus yang digunakan adalah: 


$$
N=\frac{T}{60 \times 60} \frac{P}{D E}
$$

Untuk nilai E (Efisiensi mesin dan operator) untuk semua mesin sudah ditetapkan oleh perusahaan sebesar $90 \%$ sehingga tidak perlu menghitungnya satu persatu.

Berikut ini adalah tabel lengkap hasil perhitungan jumlah mesin yang ideal yang didapatkan dibandingkan dengan jumlah mesin yang ada pada saat ini.

Tabel 3. Jumlah mesin yang dibutuhkan vs jumlah mesin saat ini

\begin{tabular}{|c|c|c|c|c|c|c|c|}
\hline No & $\begin{array}{l}\text { Nama } \\
\text { Produk }\end{array}$ & $\begin{array}{l}\text { Nama } \\
\text { Proses }\end{array}$ & $\begin{array}{l}\text { Waktu } \\
\text { Siklus } \\
\text { (detik) }\end{array}$ & $\begin{array}{l}\text { Mesin yang } \\
\text { dibutuhkan }\end{array}$ & $\begin{array}{l}\text { Mesin yang } \\
\text { dibutuhkan } \\
\text { (dibulatkan) }\end{array}$ & $\begin{array}{c}\text { Mesin yang } \\
\text { sekarang } \\
\text { ada }\end{array}$ & Saran \\
\hline \multirow{4}{*}{1} & \multirow{4}{*}{$\begin{array}{l}\text { Hub Rear } \\
2 \text { F5 }\end{array}$} & OP1 & 60 & 0,497354 & 1 & 1 & Ideal \\
\hline & & OP2 & 69 & 0,559788 & 1 & 1 & Ideal \\
\hline & & OP3 & 16 & 0,125573 & 1 & 1 & Ideal \\
\hline & & OP4 & 18 & 0,138095 & 1 & 1 & Ideal \\
\hline \multirow{5}{*}{2} & \multirow{5}{*}{$\begin{array}{l}\text { Hub Rear } \\
\text { KPW }\end{array}$} & OP1 & 54 & 1,519048 & 2 & 1 & $\begin{array}{l}\text { Perlu } \\
\text { ditambah } 1 \\
\text { mesin }\end{array}$ \\
\hline & & $\mathrm{OP} 2$ & 65 & 1,791226 & 2 & 1 & $\begin{array}{l}\text { Perlu } \\
\text { ditambah } 1 \\
\text { mesin }\end{array}$ \\
\hline & & OP3 & 68 & 1,85291 & 2 & 1 & $\begin{array}{l}\text { Perlu } \\
\text { ditambah } 1 \\
\text { mesin }\end{array}$ \\
\hline & & OP4 & 88 & 2,347443 & 3 & 1 & $\begin{array}{l}\text { Perlu } \\
\text { ditambah } 2 \\
\text { mesin }\end{array}$ \\
\hline & & OP5 & 23 & 0,600353 & 1 & 1 & Ideal \\
\hline \multirow{5}{*}{3} & \multirow{5}{*}{$\begin{array}{l}\text { Hub Fr } \\
\text { Disk } \\
\text { KWF }\end{array}$} & OP1 & 40 & 0,910053 & 1 & 1 & Ideal \\
\hline & & $\mathrm{OP} 2$ & 56 & 1,246914 & 2 & 1 & $\begin{array}{l}\text { Perlu } \\
\text { ditambah } 1 \\
\text { mesin }\end{array}$ \\
\hline & & OP3 & 46 & 0,991799 & 1 & 1 & ideal \\
\hline & & OP4 & 31 & 0,654718 & 1 & 1 & Ideal \\
\hline & & OP5 & 24 & 0,501587 & 1 & 1 & Ideal \\
\hline \multirow[t]{2}{*}{4} & \multirow{2}{*}{$\begin{array}{l}\text { JT. } \\
\text { Carburetor } \\
\text { 4D0 }\end{array}$} & OP1 & 98 & 4,398765 & 5 & 4 & $\begin{array}{l}\text { Perlu } \\
\text { ditambah } 1 \\
\text { mesin }\end{array}$ \\
\hline & & OP2 & 110 & 4,835538 & 5 & 5 & Ideal \\
\hline
\end{tabular}




\begin{tabular}{|c|c|c|c|c|c|c|c|}
\hline \multirow{5}{*}{5} & \multirow{5}{*}{$\begin{array}{l}\text { Master } \\
\text { Cylinder } \\
\text { KWFF }\end{array}$} & OP1 & 28 & 2,134568 & 3 & 3 & Ideal \\
\hline & & OP2 & 27 & 2,209524 & 3 & 3 & Ideal \\
\hline & & OP3 & 34 & 2,698413 & 3 & 3 & Ideal \\
\hline & & OP4 & 30 & 2,333333 & 3 & 3 & Ideal \\
\hline & & OP5 & 38 & 2,925397 & 3 & 3 & Ideal \\
\hline \multirow{2}{*}{6} & \multirow{2}{*}{$\begin{array}{l}\text { Master } \\
\text { Cylinder } \\
\text { KGFT }\end{array}$} & OP1 & 119 & 3,420988 & 4 & 3 & $\begin{array}{l}\text { Perlu } \\
\text { ditambah } 1 \\
\text { mesin }\end{array}$ \\
\hline & & OP2 & 113 & 3,178748 & 4 & 3 & $\begin{array}{l}\text { Perlu } \\
\text { ditambah } 1 \\
\text { mesin }\end{array}$ \\
\hline \multirow{3}{*}{7} & \multirow{3}{*}{$\begin{array}{l}\text { Master } \\
\text { Cylinder } \\
\text { KVBS }\end{array}$} & OP1 & 167 & 0,905688 & 1 & 1 & Ideal \\
\hline & & OP2 & 30 & 0,15873 & 1 & 1 & Ideal \\
\hline & & OP3 & 43 & 0,219929 & 1 & 1 & Ideal \\
\hline \multirow{4}{*}{8} & \multirow{4}{*}{$\begin{array}{l}\text { Master } \\
\text { Cylinder } \\
\text { NDF }\end{array}$} & OP1 & 23 & 1,858862 & 2 & 2 & Ideal \\
\hline & & OP2 & 22 & 1,742152 & 2 & 2 & Ideal \\
\hline & & OP3 & 25 & 1,959877 & 2 & 2 & Ideal \\
\hline & & OP4 & 36 & 2,765079 & 3 & 2 & $\begin{array}{l}\text { Perlu } \\
\text { ditambah } 1 \\
\text { mesin }\end{array}$ \\
\hline \multirow{3}{*}{9} & \multirow{3}{*}{$\begin{array}{l}\text { Caliper } \\
\text { KWFF }\end{array}$} & OP1 & 42 & 3,061111 & 4 & 3 & $\begin{array}{l}\text { Perlu } \\
\text { ditambah } 1 \\
\text { mesin }\end{array}$ \\
\hline & & OP2 & 22 & 1,570459 & 2 & 4 & $\begin{array}{l}2 \text { mesin } \\
\text { dapat } \\
\text { dikurangi }\end{array}$ \\
\hline & & OP3 & 28 & 1,977778 & 2 & 2 & Ideal \\
\hline \multirow[t]{2}{*}{10} & \multirow[t]{2}{*}{$\begin{array}{l}\text { Caliper } \\
\text { KGFT }\end{array}$} & OP1 & 83 & 2,236023 & 3 & 2 & $\begin{array}{l}\text { Perlu } \\
\text { ditambah } 1 \\
\text { mesin }\end{array}$ \\
\hline & & OP2 & 59 & 1,555644 & 2 & 2 & Ideal \\
\hline \multirow[t]{2}{*}{11} & \multirow[t]{2}{*}{$\begin{array}{l}\text { Caliper } \\
\text { KKFG }\end{array}$} & OP1 & 98 & 2,112963 & 3 & 2 & $\begin{array}{l}\text { Perlu } \\
\text { ditambah } 1 \\
\text { mesin }\end{array}$ \\
\hline & & OP2 & 58 & 1,224956 & 2 & 2 & Ideal \\
\hline \multirow{3}{*}{12} & \multirow{3}{*}{$\begin{array}{l}\text { Panel } \\
\text { KTMK }\end{array}$} & OP1 & 13 & 0,672354 & 1 & 1 & Ideal \\
\hline & & OP2 & 29 & 1,484524 & 2 & 1 & $\begin{array}{l}\text { Perlu } \\
\text { ditambah } 1 \\
\text { mesin }\end{array}$ \\
\hline & & OP3 & 25 & 1,253307 & 2 & 1 & $\begin{array}{l}\text { Perlu } \\
\text { ditambah } 1 \\
\text { mesin }\end{array}$ \\
\hline \multirow{3}{*}{13} & \multirow{3}{*}{$\begin{array}{l}\text { Panel } \\
\text { KCPV }\end{array}$} & OP1 & 26 & 0,382892 & 1 & 1 & Ideal \\
\hline & & OP2 & 25 & 0,36045 & 1 & 1 & Ideal \\
\hline & & OP3 & 30 & 0,306878 & 1 & 1 & Ideal \\
\hline
\end{tabular}




\begin{tabular}{|c|l|c|c|c|c|c|l|}
\hline \multirow{2}{*}{14} & \multirow{2}{*}{ FFD NDF } & OP1 & 108 & 0,533333 & 1 & 1 & Ideal \\
\cline { 3 - 8 } & & OP2 & 108 & 0,514286 & 1 & 1 & Ideal \\
\hline \multirow{3}{*}{15} & \multirow{2}{*}{$\begin{array}{l}\text { FFD } \\
\text { KWFF }\end{array}$} & OP1 & 50 & 1,097884 & 2 & 2 & Ideal \\
\cline { 3 - 8 } & & OP2 & 40 & 0,86067 & 1 & 2 & $\begin{array}{l}\text { mesin } \\
\text { dapat } \\
\text { dikurangi }\end{array}$ \\
\cline { 3 - 8 } & & OP3 & 24 & 0,50582 & 1 & 1 & Ideal \\
\hline
\end{tabular}

\section{KESIMPULAN}

Hasil pengecekan terhadap jumlah mesin menunjukkan bahwa agar tercapainya keseimbangan lintasan produksi sehingga nantinya dapat meningkatkan kapasitas produksi, terdapat tiga macam tindakan yang dapat diambil yaitu :

a. Penambahan mesin

Penambahan mesin artinya perusahaan disarankan menambah jumlah mesin tertentu agar kapasitas atau permintaan dari konsumen dapat dipenuhi. Beberapa mesin yang memerlukan penambahan satu unit mesin adalah OP1, OP2, dan OP3 untuk part Hub Rear KPW; OP2 untuk part Hub Fr Disk KWF; OP1 untuk part JT. Carburetor 4D0, OP1, OP2 untuk part Master Cylinder KGFT; OP4 untuk part Master Cylinder NDF; OP1 untuk part Caliper KWFF; OP1 untuk part Caliper KGFT; OP1 Caliper KKFG; OP2, OP3 untuk part Panel KTMK. Mesin yang memerlukan penambahan dua unit adalah OP4 untuk Hub Rear KPW.

b. Pengurangan mesin

Pengurangan mesin artinya perusahaan memungkinkan untuk mengurangi mesin tertentu dan memindahkan/mengalihkan operatornya untuk mesin yang lain yang memerlukan penambahan mesin. hal ini bertujuan untuk efisiensi perusahaan. Beberapa mesin yang dapat dikurangi diantaranya 2 unit mesin OP2 untuk part Caliper KWFF dan 1 unit mesin OP2 untuk part FFD KWFF.

c. Sudah ideal

Sudah ideal artinya jumlah mesin yang ada sama dengan jumlah mesin yang dibutuhkan sehingga tidak diperlukan penambahan ataupun pengurangan.

\section{DAFTAR PUSTAKA}

Heizer, J., \& Render, B. (2004). Operations Management, Edisi 7. New Jersey: Prentice-Hall.

Nasution, A. H. (2006). Manajemen Industri. Yogyakarta: Andi Offset.

Wignjosoebroto, S. (1996). Tata Letak Pabrik dan Pemindahan Bahan, Edisi ke-3. Surabaya: Guna Widya. 